\title{
A Parameterization of Intermittent Turbulence in the Stable Boundary Layer
}

\author{
E.N. Nitao, J.K. Lundquist, G.A. Loosmore
}

August 1, 2003

U.S. Department of Energy

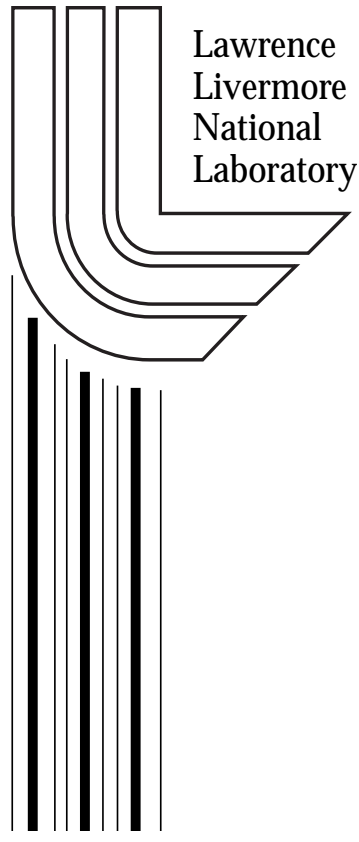




\section{DISCLAIMER}

This document was prepared as an account of work sponsored by an agency of the United States Government. Neither the United States Government nor the University of California nor any of their employees, makes any warranty, express or implied, or assumes any legal liability or responsibility for the accuracy, completeness, or usefulness of any information, apparatus, product, or process disclosed, or represents that its use would not infringe privately owned rights. Reference herein to any specific commercial product, process, or service by trade name, trademark, manufacturer, or otherwise, does not necessarily constitute or imply its endorsement, recommendation, or favoring by the United States Government or the University of California. The views and opinions of authors expressed herein do not necessarily state or reflect those of the United States Government or the University of California, and shall not be used for advertising or product endorsement purposes.

This work was performed under the auspices of the U. S. Department of Energy by the University of California, Lawrence Livermore National Laboratory under Contract No. W-7405-Eng-48.

This report has been reproduced directly from the best available copy.

Available electronically at http://www.doe.gov/bridge

Available for a processing fee to U.S. Department of Energy

and its contractors in paper from

U.S. Department of Energy

Office of Scientific and Technical Information

P.O. Box 62

Oak Ridge, TN 37831-0062

Telephone: (865) 576-8401

Facsimile: (865) 576-5728

E-mail: reports@adonis.osti.gov

Available for the sale to the public from

U.S. Department of Commerce

National Technical Information Service

5285 Port Royal Road

Springfield, VA 22161

Telephone: (800) 553-6847

Facsimile: (703) 605-6900

E-mail: orders@ntis.fedworld.gov

Online ordering: http://www.ntis.gov/ordering.htm

OR

Lawrence Livermore National Laboratory

Technical Information Department's Digital Library

http://www.llnl.gov/tid/Library.html 


\section{A Parameterization of Intermittent Turbulence in the Stable Boundary Layer \\ E. N. Nitao, J. K. Lundquist, G. A. Loosmore \\ Atmospheric Science Division \\ Lawrence Livermore National Laboratory, Livermore, CA \\ August, 2003}

\section{Introduction to Turbulence and Intermittency in the Stable Boundary Layer}

The atmospheric boundary layer is of special interest due to its direct impact and interaction with the surface of the earth where most human activity occurs. The daytime boundary layer is dominated by convective turbulence, and thus is modeled easily. However, sources of turbulence at night are multipled and varied, making the flow more difficult to predict (Derbyshire, 1999). And yet it is important to predict nocturnal dynamics because of its influences on aviation, the dispersion of pollutants, and fog formation.

The boundary layer consists of approximately the $1^{\text {st }} \mathrm{km}$ of atmosphere above the earth's surface. During the day, solar radiation heats the ground, which in turn heats the layer of air closest to the ground. This source of heat causes turbulence or a mixing of air due to the convection process. When the sun sets, the earth's surface begins to cool due to the absence of solar radiation. Thus, a temperature inversion is created. The region capped by the inversion is known as the stable boundary layer (Stull, 1988). In contrast to the continuous turbulence of the daytime boundary layer, the stable boundary layer has been observed to be intermittently turbulent on nights of weak winds and little cloud cover. Figure 1 exhibits these nocturnal oscillations in surface temperature from 400 to 1300 Universal Time Code (2300 to 800 Local Standard Time) contrasted with a smooth increase in temperature during and after sunrise, very small fluctuations during the day, and a smooth decrease in temperature at sunset.

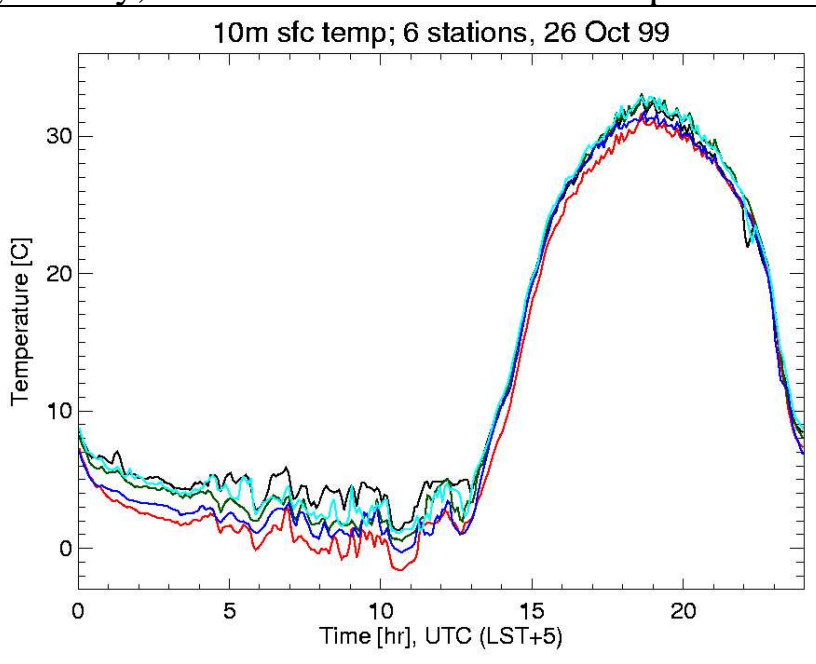

Fig. 1. Surface temperatures in Kansas from the CASES99 field experiment on the clear night of 25-26 October 1999 with winds less than $8 \mathrm{~m} / \mathrm{s}$. The different color lines refer to different stations a few hundred meters apart. Notice the oscillations in temperature during the night contrasted with the smooth increase in temperature during and after sunrise. (Figure provided by J. K. Lundquist, jkl@llnl.gov) 
Since the main source of convective turbulence, solar radiation, is no longer present after sunset, weaker sources of turbulence have a greater effect on the thermal stability of the atmosphere (Stull, 1988). Disregarding the influence of the atmosphere above the stable boundary layer, one intermittent turbulence mechanism can be described as follows. As the ground begins to cool (radiative cooling), thermal stability increases, causing turbulence to decrease. Once turbulence decreases to a certain point, the flow from high to low pressure dominates and the winds begin to increase, generating turbulence again. This turbulent flow, in turn, damps the wind speed, and the radiative cooling of the earth's surface dominates the air flow, setting the system up for another cycle of intermittent turbulence. This cyclic increase and decrease of turbulence leads to oscillations in the sensible heat flux, surface temperature, air temperature, wind speed, and other quantities that describe the system (van de Wiel et al., 2002a).

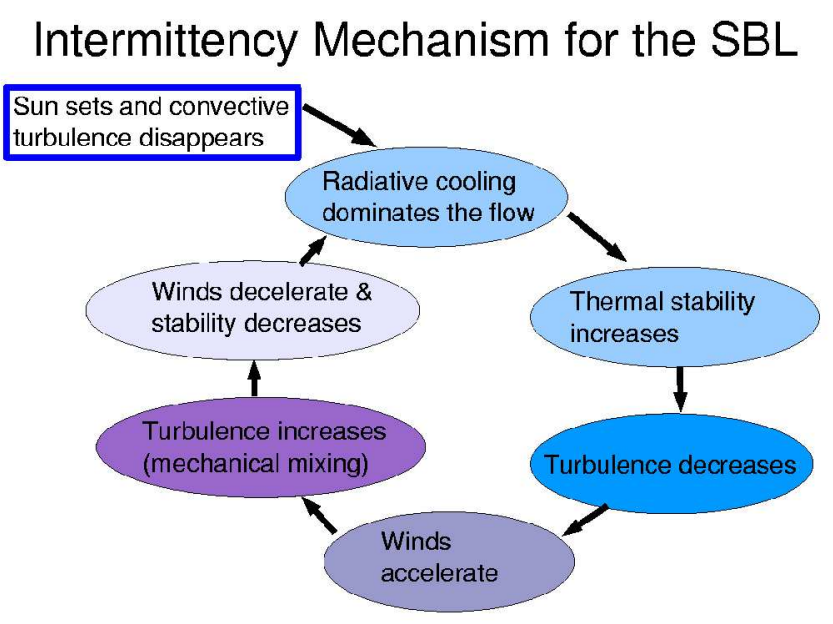

Fig. 2. A graphical representation of a mechanism for intermittent turbulence. (Figure provided by J. K. Lundquist, jkl@1lnl.gov)

In exploring this type of intermittent turbulence with a simple model, we seek to quantify the period, amplitude, and time to transition to a quasi-steady state and parameterize these quantities as a function of the input variables pressure gradient force, cloud cover fraction, and boundary layer height.

\section{Description of the model}

The working model is based on van de Wiel et al.'s (2002a) slab-model parameterization of the stable boundary layer, which incorporates the interaction between a low vegetated/mulch surface and the lower atmosphere (van de Wiel et al., 2002a). The thickness and conductivity of the mulch layer are presented by $\delta_{m}$ and $\lambda_{m}$, respectively. All quantities are considered in the $\mathrm{u}$ direction and averaged over the boundary layer height.

The simplicity of the model lies in the fact that only three input parameters - the pressure 
gradient force (PGF), the cloud cover fraction (N), and the boundary layer height (h) - are required to generate timeseries for the wind speed $(U)$, the air temperature $\left(T_{a}\right)$, the surface temperature $\left(\mathrm{T}_{\mathrm{s}}\right)$, the frictional velocity $\left(\mathrm{u}_{\text {star }}\right)$, and the bulk Richardson number (R_b). The rest of the parameters are fixed. A brief description of the required input quantities are as follows. The pressure gradient force PGF represents the flow from high pressure to low pressure in the $\mathrm{u}$ direction. It is the product of the Coriolis parameter $\mathrm{f}$ (taken as a constant $1.0 * 10^{-4}$ $1 / \mathrm{s}$ ) and the geostrophic wind $\mathrm{u}_{\mathrm{g}}$. The cloud cover fraction $\mathrm{N}$ indicates the amount of overhead clouds. A cloud cover fraction of 0.0 refers to a clear sky whereas a cloud cover fraction of 1.0 refers to a completely overcast sky. The boundary layer height $\mathrm{h}$ is considered to be the top of the temperature inversion and is held constant for most of the simulations discussed.

Table 1. The parameters and the values that are used in the model runs. Variations from the van de Wiel et al. model are in bold. Note Table 1 continues on the next page.

\begin{tabular}{|c|c|c|c|}
\hline Parameter & Description & Value & Units \\
\hline$t_{0}$ & Initial time & 0 & $\mathrm{~s}$ \\
\hline$t_{f}$ & Final time & $1.44 \times 10^{\wedge}(5)$ & $\mathrm{s}$ \\
\hline$t_{\text {step }}$ & Time step & 10 & $\mathrm{~s}$ \\
\hline$U_{0}$ & Initial wind speed & 7 & $\mathrm{~m} / \mathrm{s}$ \\
\hline$T_{a 0}$ & Initial air temperature & 285 & $\mathrm{~K}$ \\
\hline$T_{s o}$ & Initial surface temperature & 285 & $\mathrm{~K}$ \\
\hline $\begin{array}{l}\frac{1}{\rho} \frac{\partial P}{\partial s} \\
\text { or PGF }\end{array}$ & $\begin{array}{l}\text { Effective pressure force (per } \\
\text { mass) }\end{array}$ & $\begin{array}{c}1.0 * 10^{-4} *[0, .1, .2, .3 \\
.4, \\
.5, .75, \ldots, 2.0^{1}, \ldots .14 .75 \\
15.0]\end{array}$ & $\mathrm{m} / \mathrm{s}^{2}$ \\
\hline$N$ & Cloud fraction & $0.0,0.05, \ldots, 0.95,1.0$ & - \\
\hline$z_{0}$ & Roughness length & 0.05 & $\mathrm{~m}$ \\
\hline$\epsilon_{a}$ & Air emissivity & 0.78 & - \\
\hline$\epsilon_{s}$ & Surface emissivity & 1 & - \\
\hline$C_{v}$ & $\begin{array}{l}\text { Heat capacity per } \mathrm{m}^{2} \text { of low } \\
\text { vegetated surface }\end{array}$ & $2.0 \times 10^{\wedge}(3)$ & $\mathrm{J} /\left(\mathrm{m}^{2} \mathrm{~K}\right)$ \\
\hline$\lambda_{m} / \delta_{m}$ & $\begin{array}{l}\text { Bulk conductance of } \\
\text { mulch/stagnant air layer }\end{array}$ & 2.5 & $\mathrm{~W} /\left(\mathrm{m}^{2} \mathrm{~K}\right)$ \\
\hline$T_{r e f}$ & Reference temperature & 285 & K \\
\hline$T_{M}$ & Soil temperature & 285 & $\mathrm{~K}$ \\
\hline$T_{t o p}$ & $\begin{array}{l}\text { Temperature above the boundary } \\
\text { layer }\end{array}$ & 285 & $\mathrm{~K}$ \\
\hline$h$ & Boundary layer height & $\mathbf{4 0}, \mathbf{5 0}, \ldots, 80, \ldots, \mathbf{1 9 0 , 2 0 0}$ & $\mathrm{m}$ \\
\hline
\end{tabular}

1 Table 1 in van de Wiel et al., 2002a incorrectly lists the pressure gradient force as a positive $2.0 \times 10^{\wedge}(-4)$ 


\begin{tabular}{|c|c|c|c|}
\hline Parameter & Description & Value & Units \\
\hline$\tilde{h}$ & Reference height $(\mathrm{h} / 2)$ & $20,25, \ldots ., 40, \ldots ., 95,100$ & $\mathrm{~m}$ \\
\hline$f$ & Coriolis parameter & $1.0 * 10^{-4}$ & $1 / \mathrm{s}$ \\
\hline$c_{p}$ & $\begin{array}{l}\text { Heat capacity of dry air @ } \\
\text { constant pressure }\end{array}$ & 1005 & $\mathrm{~J} /(\operatorname{kg~K})$ \\
\hline$\rho$ & Density of dry air & 1.2 & $\mathrm{~kg} / \mathrm{m}^{3}$ \\
\hline$R_{c}$ & Critical bulk Richardson number & 0.2 & - \\
\hline$g$ & Gravity constant & 9.81 & $\mathrm{~m} / \mathrm{s}^{2}$ \\
\hline$\kappa$ & von Karman constant & 0.4 & - \\
\hline$\sigma$ & Boltzmann's constant & $5.67 * 10^{-8}$ & $\mathrm{~J} /\left(\mathrm{K}^{4} \mathrm{~s} \mathrm{~m}^{2}\right)$ \\
\hline
\end{tabular}

The following equations are used to describe the system in terms of the bulk wind speed $\mathrm{U}$, air temperature $\mathrm{T}_{\mathrm{a}}$, and surface temperature $\mathrm{T}_{\mathrm{s}}$.

$$
\int \frac{\partial U}{\partial t} d z=h \frac{\partial U}{\partial t}=\frac{-h}{\rho} \frac{\partial P}{\partial s}+\frac{1}{\rho}\left(\tau_{h}-\tau_{0}\right)
$$

where the pressure gradient force is

$$
\frac{1}{\rho} \frac{\partial P}{\partial s}=-f * u_{g}
$$

$u_{g}$ is the geostrophic wind, $\tau_{h}=0$, and

$$
\begin{aligned}
& \boldsymbol{\tau}_{0}=\rho u_{\text {star }}^{2}=\rho U^{2} \frac{\kappa^{2}}{\left[\ln \left(\tilde{h} / z_{0}\right)\right]^{2}} f\left(R_{b}\right) \\
& \int \frac{\partial T_{a}}{\partial t} d z=h \frac{\partial T_{a}}{\partial t}=\frac{1}{\left(\rho c_{\rho}\right)}\left(R_{h}-R_{0}\right)-\frac{1}{\left(\rho c_{\rho}\right)}\left(H_{h}-H_{0}\right)
\end{aligned}
$$

where

$$
\begin{aligned}
& R_{h}-R_{o}=\epsilon_{a} \sigma\left(T_{\text {top }}^{4}-2 T_{a}^{4}+T_{s}^{4}\right) \\
& \left(H_{h}-H_{0}\right)=\rho c_{p}|U| \Delta T \frac{\kappa^{2}}{\left[\ln \left(\widetilde{h} / z_{0}\right)\right]^{2}} f\left(R_{b}\right) \\
& H_{h}=0, \quad \Delta T=T_{a}-T_{s}
\end{aligned}
$$

2 Table 1 in van de Wiel et al. 2002a incorrectly leaves out the $\mathrm{m}^{\wedge}(-2)$ in the units for the Boltzmann's constant. 


$$
\int \frac{\partial T_{s}}{\partial t} d z=d \frac{\partial T_{s}}{\partial t}=\frac{-1}{\left(\rho c_{v}\right)}\left(G_{d}-G_{0}\right)
$$

where

$$
\begin{aligned}
& G_{0}=\frac{-1}{C_{v}} \frac{\lambda_{m}}{\delta_{m}}\left(T_{s}-T_{M}\right) \\
& G_{d}=-Q_{n e t}+H_{0}
\end{aligned}
$$

Radiation terms: $Q_{n e t}=\epsilon_{a} \sigma T_{a}^{4}+60 N-\epsilon_{s} \sigma T_{s}^{4}$,

$\mathrm{N}$ is the cloud cover fraction, and $\mathrm{d}$ is the vegetation/soil depth.

The bulk Richardson number is defined as

$$
R_{b}=\left(\tilde{h}-z_{0}\right) \frac{g}{T_{r e f}} \frac{\Delta T}{U^{2}}
$$

The stability function is defined as

$$
\begin{aligned}
& f\left(R_{b}\right)=\left(1-\frac{R_{b}}{R_{c}}\right)^{2} \text { for } 0 \leq R_{b} \leq R_{c} \\
& f\left(R_{b}\right)=0 \text { for } R_{b}>R_{c}
\end{aligned}
$$

Substituting, the equations become:

$$
\begin{aligned}
& \frac{\partial U}{\partial t}=\frac{-1}{\rho} \frac{\partial P}{\partial s}-\frac{1}{h} \frac{\kappa^{2}}{\left[\ln \left(\tilde{h} / z_{0}\right)\right]^{2}} U^{2} f\left(R_{b}\right) \\
& \frac{\partial T_{a}}{\partial t}=\epsilon_{a} \sigma \frac{\left(T_{t o p}^{4}-2 T_{a}^{4}+T_{s}^{4}\right)}{\rho c_{\rho} h}-\frac{1}{h} \frac{\kappa^{2}}{\left[\ln \left(\tilde{h} / z_{0}\right)\right]^{2}} U\left(T_{a}-T_{s}\right) f\left(R_{b}\right) \\
& \frac{\partial T_{s}}{\partial t}=\frac{-1}{C_{v}}\left(\varepsilon_{a} \sigma T_{a}^{4}+60 N-\varepsilon_{s} T_{s}^{4}\right)+\frac{\rho c_{\rho}}{C_{v}} \frac{\kappa^{2}}{\left[\ln \left(\tilde{h} / z_{0}\right)\right]^{2}} U\left(T_{a}-T_{s}\right) f\left(R_{b}\right)-\frac{1}{C_{v}} \frac{\lambda_{m}}{\delta_{m}}\left(T_{s}-T_{M}\right)
\end{aligned}
$$

The wind speed equation (Equ. 1 \& 12) consists of the pressure gradient force and the difference in shear stress (frictional velocity $\mathrm{u}_{\text {star }}$ ) at the top and bottom of the boundary layer. The air temperature (Equ. $4 \& 13$ ) is affected by the net longwave radiation and the turbulent heat flux at the top and bottom of the boundary layer. Lastly, the surface temperature (Equ. $7 \&$ 14 ) is simply due to the energy flux at the top of the vegetative surface and the soil heat flux. Note that in the van de Wiel et al. (2002a) paper, the radiation terms in the temperature 
equations are linearized to be proportional to the air and surface temperatures. This linear approximation is essential for the analysis in van de Wiel et al. (2002b). However, for our purposes, we have used the original definition of net radiation with air and surface temperature to the fourth power (Equ. $5 \&$ 9). Also of interest is the stability function (Equ. 11), the definition of the bulk Richardson number (Equ. 10), and the value of the critical Richardson number (Table 1).

The equations are solved using a fourth-order Runge-Kutta method with a time step of ten seconds over a time period of 40 hours. Additionally, the code allows the pressure gradient force, cloud cover fraction, boundary layer height, reference boundary layer height, and bulk conductance parameter to vary with time.

\section{Data-processing}

First, the simulations investigate the behavior of the system with parameters that are constant in time. Each simulation differs from the rest by a unique combination of the pressure gradient force (PGF), cloud cover fraction $(\mathrm{N})$, and boundary layer height $(\mathrm{h})$. The reference boundary layer height $(\mathrm{h} / 2)$ changes depending on the boundary layer height. The model is run for $|\mathrm{PGF}|$ of $0,1.0 * 10^{-5}, 2.0 * 10^{-5}, 3.0 * 10^{-5}, 4.0 * 10^{-5}, 5.0 * 10^{-5}$,

$7.5 * 10^{-5}, 1.0 * 10^{-4}, 1.25 * 10^{-4}, 1.5 * 10^{-4}, \ldots, 14.75 * 10^{-4}, 15.0 * 10^{-4} \mathrm{~m} / \mathrm{s}^{2}$ with increments of $1.0 * 10^{-5} \mathrm{~m} / \mathrm{s}^{2}$ for values 0 to $5.0 * 10^{-5} \mathrm{~m} / \mathrm{s}^{2}$ and increments of $2.5 * 10^{-5} \mathrm{~m} / \mathrm{s}^{2}$ for values from $5.0 * 10^{-5}$ to $15.0 * 10^{-4} \mathrm{~m} / \mathrm{s}^{2}$, cloud cover fractions ranging from 0 to 1.0 with increments of .05 , and boundary layer heights from 40 to $200 \mathrm{~m}$ with increments of $10 \mathrm{~m}$. A total of 22,848 runs are generated.

The intermittency in the timeseries is defined by the period of quasi-steady oscillations, the amplitude of those oscillations, and the time to transition to this steady oscillating state. The surface temperature is used for this analysis since all other quantities oscillate similarly, and the magnitude of its amplitude is greater than the other quantities (wind speed and air temperature), which assists in the processing and comparison.

The surface temperature amplitude is calculated by taking the average difference between the maximum and minimum temperature envelopes over the last 20 hours of the timeseries. If the amplitude is less than .1 degree Kelvin, the timeseries is considered nonintermittent.

To calculate the period of an intermittent timeseries, the mean envelope of the timeseries is calculated, and the average difference between the times that the mean envelope intersects the rising edge of the timeseries over the last 20 hours is used. The obvious method of computing a Fast Fourier transform of the timeseries and looking at the power spectrum has not been used due to the interference of the transition time oscillations. An alternative is to compute the Fast Fourier transform over the last half of the timeseries; however, an inaccurate period is calculated if that portion of the timeseries only consists of a few cycles or if the period exceeds 6 hours.

The transition time for all timeseries is obtained by finding the latest time where a specific value that represents the last half of the mean envelope timeseries exceeds the mean envelope by $.15 \%$. If the timeseries is intermittent, the comparison point is located at the first intersection of the mean envelope with the last half of the temperature timeseries. Otherwise, the last value of the mean envelope is used. 


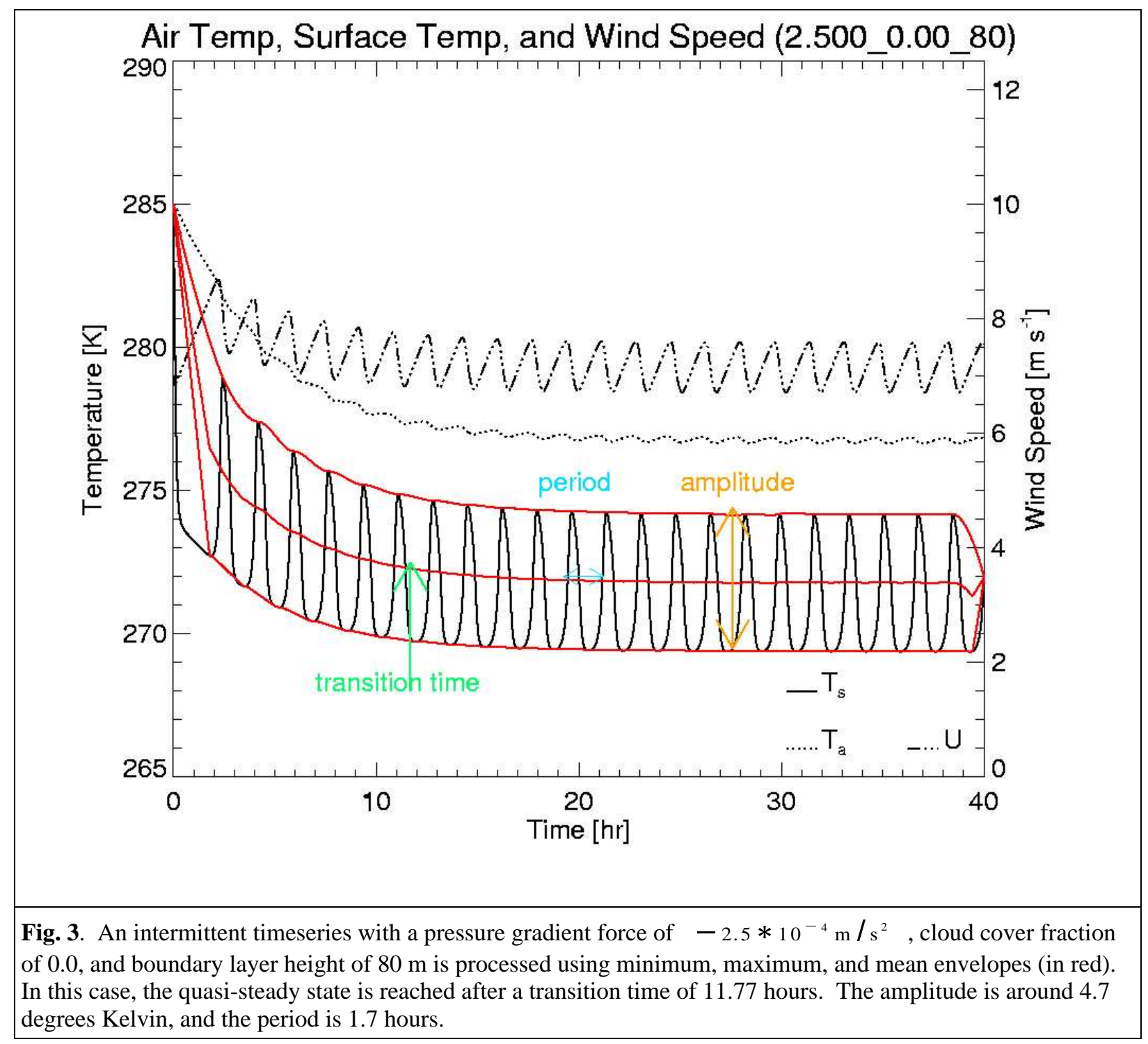

Following this criteria, only $12.6 \%$ of the simulations are considered intermittent. Of these intermittent cases, $91.8 \%$ of them have periods between .9 hours and 5 hours; the distribution of periods can be seen in Figure 4. The amplitudes range from 0 to 7 degrees Kelvin, and the transition times for the intermittent cases are less than 26 hours.

The periods and amplitudes of the frictional velocity $\mathrm{u}_{\text {star }}$ and the sensible heat flux $\mathrm{H}_{0}$ may also be of interest to the reader. As mentioned before, $\mathrm{u}_{\text {star }}$ and $\mathrm{H}_{0}$ have the same periods as the surface temperature. The amplitudes of these quantities can be described in terms of the surface temperature (Equ. 15 \& 16, Fig. 5).

$$
\begin{aligned}
& \text { Amplitude of ustar }=0.0675 * \text { Amplitude of } \mathrm{T}_{\mathrm{s}}+0.02706 \\
& \text { Amplitude of } \mathrm{H}_{\mathrm{o}}=7.985 * \text { Amplitude of } \mathrm{T}_{\mathrm{s}}-0.04161
\end{aligned}
$$




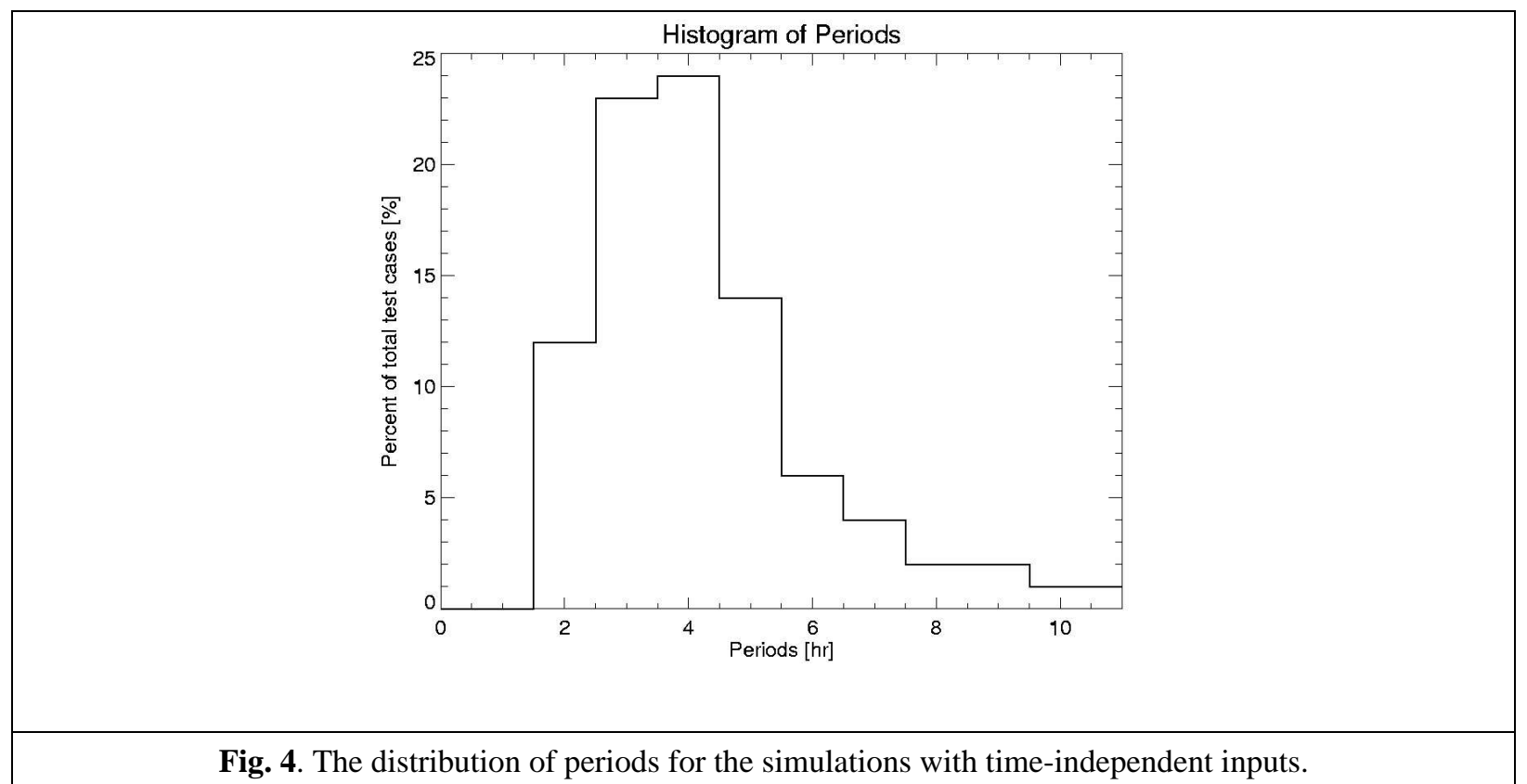

To better represent the majority of the sensible heat flux, data points above $100 \mathrm{~W} / \mathrm{m}^{2}$ have been neglected; however, these points consist of only $1 \%$ of the intermittent cases. The variation in data points for $\mathrm{u}_{\text {star }}$ versus $\mathrm{T}_{\mathrm{s}}$ may be caused by the inadequate calculation of amplitude. The relationship between the quantities may improve if the amplitude is calculated by averaging the mean envelope from the transition time and on, instead of averaging the mean envelope over the last 20 hours. It is not obvious if this will indeed improve the calculation since the maximum transition time calculated is less than 26 hours.

\section{Variability of intermittency with PGF, $N$ and $h$}

Contour plots are used as a way to view the periods, amplitudes and transition times as functions of the pressure gradient force, boundary layer height, and cloud cover fraction. Some observations are that intermittency does not occur for $|\mathrm{PGF}|$ less than $3.0 * 10^{-5} \mathrm{~m} / \mathrm{s}^{2}$ and $|\mathrm{PGF}|$ greater than $5.0 * 10^{-4} \mathrm{~m} / \mathrm{s}^{2}$; however, one cannot conclude that all other cases are intermittent. Intermittency is also restricted to cloud cover fractions less than .95. Also noteworthy is that intermittency occurs for combinations of high magnitude pressure gradient force and low boundary layer height or low magnitude pressure gradient force and high boundary layer height (Fig. 6).

Table 2 lists some effects that the input parameters have on the intermittency. Some hypotheses for these trends are explained:

a) For a large magnitude pressure gradient force, the cycle of generating and suppressing turbulence occurs faster. At a very high magnitude pressure gradient force, the force dominates the flow and cannot be overcome. Thus, the turbulence cannot be suppressed and no 
intermittency occurs.

b) As the cloud cover increases, it acts as an insulation, trapping more heat, and it emits more radiation, causing more mixing to take place. Consequently, the timeseries approaches a quasi-steady state faster for higher cloud cover fractions, resulting in a shorter transition time. The timeseries also does not reach as low temperatures as its lower cloud cover fraction counterparts so the amplitudes are smaller.

c) As the boundary layer heights increase, the interaction between the clouds and ground is limited. Thus, the frequency of turbulence increases and similar to b) the transition times and amplitudes increase.

Table 2. Intermittency vs. input parameters

\begin{tabular}{|l|c|c|c|}
\hline & $|\boldsymbol{P G F}|$ increases & N increases & $\boldsymbol{h}$ increases \\
\hline Periods $(\boldsymbol{P})$ & P decreases & ------------ & P increases \\
\hline Amplitudes $(\boldsymbol{A})$ & ----------- & A decreases & A increases \\
\hline $\begin{array}{l}\text { Transition Times } \\
(\boldsymbol{T T})\end{array}$ & ------------ & TT decreases & TT increases \\
\hline
\end{tabular}



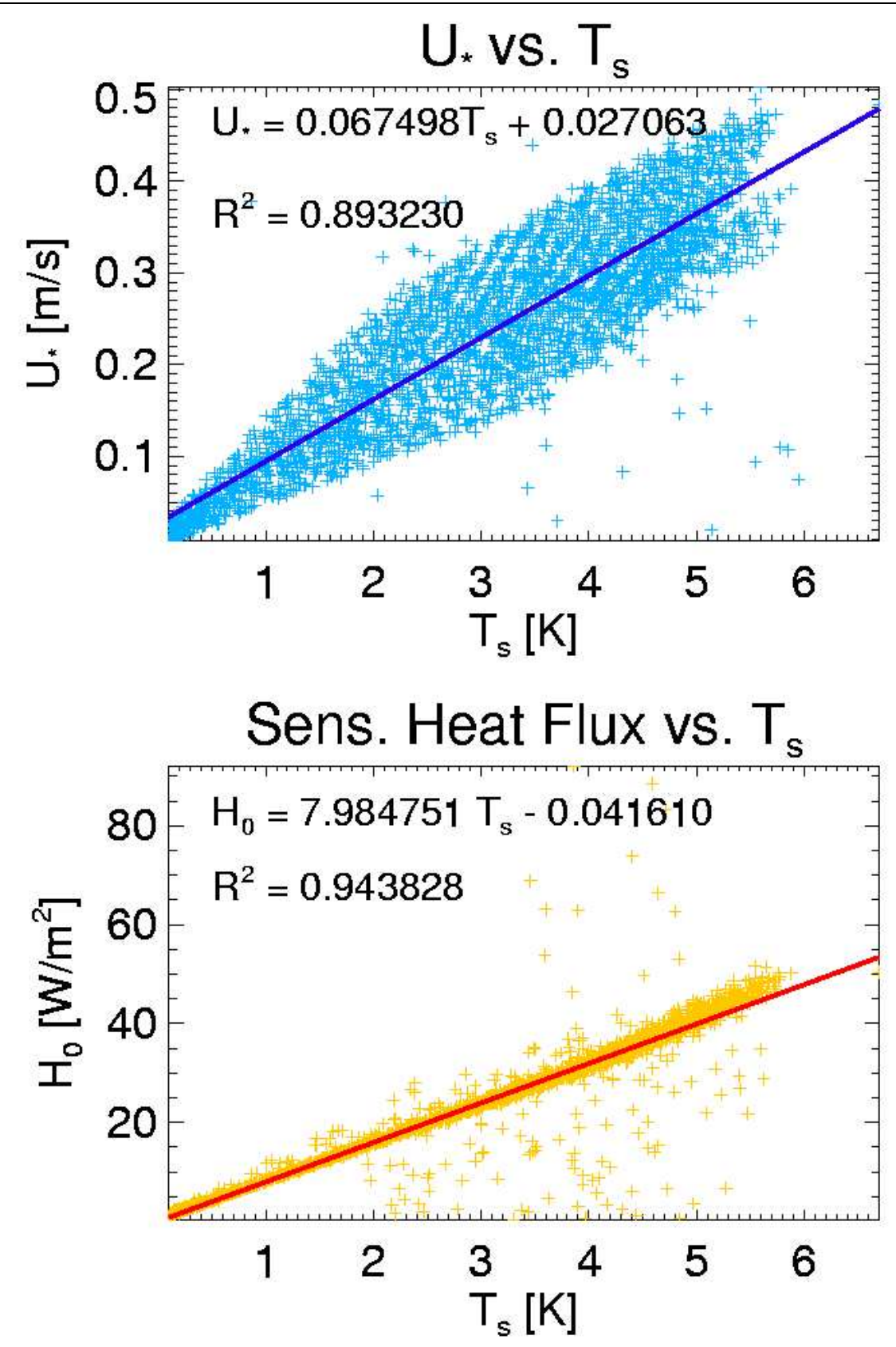

Fig. 5. a) Amplitude of $u_{\text {star }}$ vs. surface temperature. b) Amplitude of sensible heat flux versus surface temperature. 


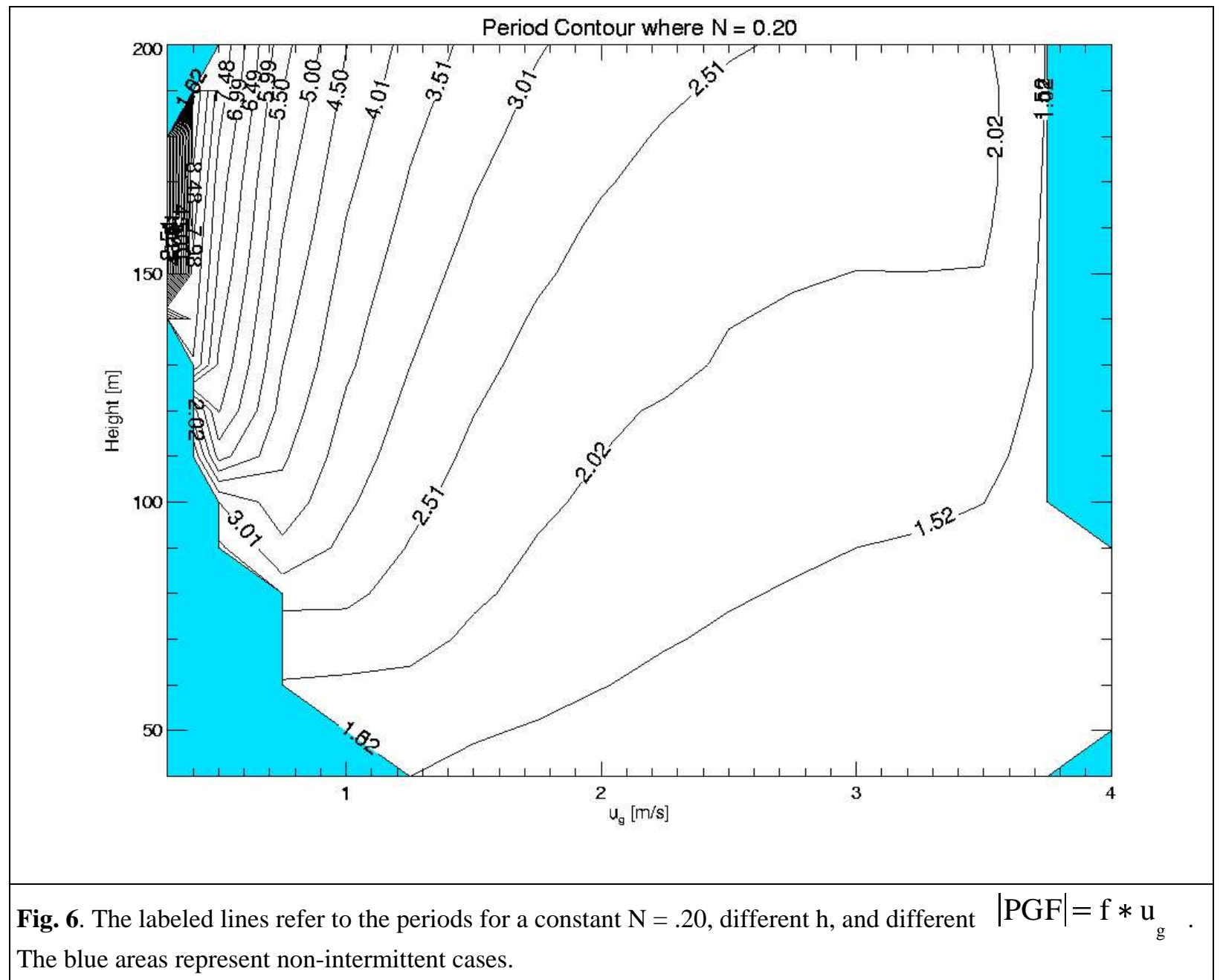

\section{Parameterization of Intermittency}

To predict intermittency, the van de Wiel et al. paper has defined time-scaled, velocityscaled, and temperature-scaled parameters to develop a criteria for intermittency using the nondimensional number PI (van de Wiel et al., 2002b). Assuming intermittency exists for a certain combination of the input parameters (perhaps using PI), my analysis claims that the periods of intermittency can be determined using the scaled time parameter and temperature parameter. This implies that the three input parameters, PGF, N, and h, may be sufficient to define the frequency of intermittency, where the intermittent turbulence is predominantly a result of the surface-atmosphere interaction.

The first studied parameter is the time parameter (Equ. 17) It has been modified from its form in the van de Wiel et al. paper to represent a non-dimensional number (Equ. 18). 


$$
\begin{aligned}
& \text { Timescale }: \tau_{\mathrm{bl}}[\mathrm{s}]=\sqrt{\frac{\mathrm{h}}{\frac{-1}{\rho} \frac{\partial \mathrm{P}}{\partial \mathrm{s}}}}=\sqrt{\frac{\mathrm{h}}{-\mathrm{PGF}}}=\sqrt{\frac{\mathrm{h}}{\mathrm{f} * \mathrm{u}_{\mathrm{g}}}} \\
& \text { where } \mathrm{f} \text { is a Coriolis parameter of } 1.0 * 10^{-4} \quad 1 / \mathrm{s} \\
& \text { Non }- \text { dimensional number } \mathrm{F}=\left(\mathrm{f} * \tau_{\mathrm{bl}}\right)^{2}=\frac{\mathrm{f}^{2} * \mathrm{~h}}{-\mathrm{PGF}}=\frac{\mathrm{f}^{2} * \mathrm{~h}}{\mathrm{f} * \mathrm{u}_{\mathrm{g}}}
\end{aligned}
$$

The advantage of a non-dimensional number is that it can be incorporated into different quantities without the need to be scaled. By plotting different periods versus the nondimensional number, one can see that a well-fitted linear regression line can be drawn through data points that share the same cloud cover fraction (Fig. 7). Plotting the slopes and intercepts of these regression lines, it appears that the slopes decrease linearly and the intercepts increase quadratically as the cloud cover fraction increases.

The goodness-of-fit of the line to the data is measured by a correlation coefficient where a correlation coefficient of 1.0 is a good fit and one of 0.0 is a poor fit. These coefficients are obtained from the IDL procedure REGRESS. When the IDL function REGRESS is not used, the normalized root mean square (Equ. 19) is calculated by taking the square root of the average sum of the squares of the differences between the data and fitted data points and normalized by the standard deviation $\sigma$ of the original data.

$$
\text { Normalized rms }=\frac{1}{\sigma} \sqrt{\frac{\sum\left(y_{\text {data }}-y_{f t}\right)^{2}}{n}}
$$

where $\mathrm{n}$ is the total number of data points. An normalized rms close to 0 is a good fit, and a normalized rms close to 1.0 is considered a poor fit.

Notice that the slopes and intercepts where the correlation coefficient is less than .9 are not included in the fit. Combining the results of the fitted curves, the periods can be defined as

$$
\mathrm{P}=1.445 \mathrm{~N}^{2}-(244.6 \mathrm{~F}+0.337) \mathrm{N}+230.3 \mathrm{~F}+0.989
$$

Therefore, by simply knowing the pressure gradient force, the cloud cover fraction, and the boundary layer height, the frequency of intermittency can be determined in terms of the nonmensional number F.

Periods are also related to the temperature parameter (Equ. 21).

$$
\begin{aligned}
& \text { Temperature scale }[\mathrm{K}]: \mathrm{T}_{\mathrm{k}}=\frac{\left|\mathrm{Q}_{\mathrm{i}}\right| \boldsymbol{\tau}_{\mathrm{bl}}}{\mathrm{C}_{\mathrm{v}}} \\
& \text { where } Q_{i}=-\sigma\left(\varepsilon_{s}-\varepsilon_{a}\right) T_{r e f}^{4}+60 N .
\end{aligned}
$$


Since the period data are grouped fairly close together, a quadratic curve can be fitted to the data with a normalized rms of .08. Thus the periods can be described in terms of the temperature parameter as

$$
\mathrm{P}=0.00119 \mathrm{~T}_{\mathrm{k}}^{2}+0.0194 \mathrm{~T}_{\mathrm{k}}+0.775
$$

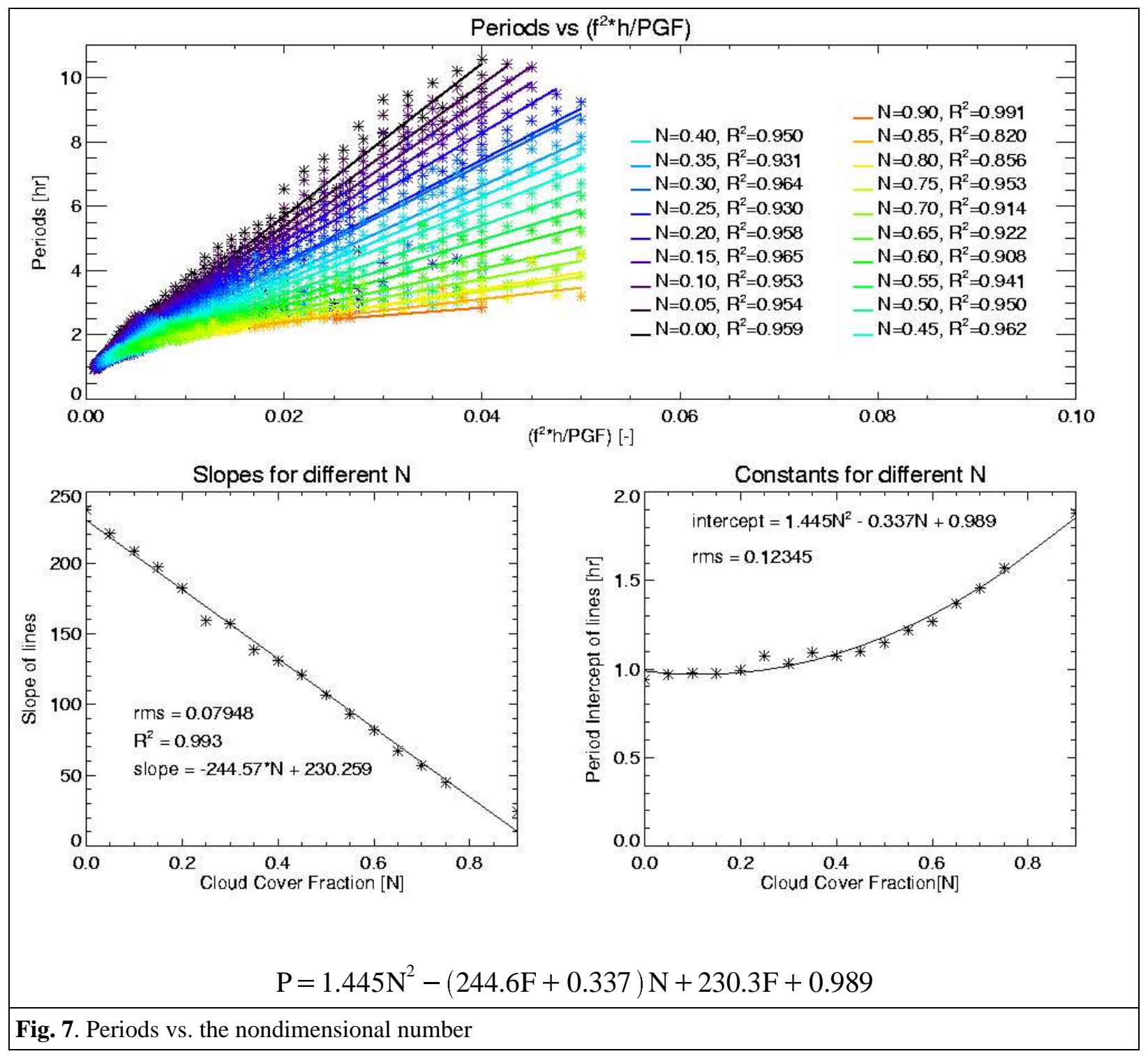


Looking at Figure 8, there are quite a few points below the curve and some far above it. These points correspond to a combination of $|\mathrm{PGF}|$ below $1.25 * 10^{-4} \mathrm{~m} / \mathrm{s}^{2}$ and cloud cover fractions below .4. It is advised to use the non-dimensional parameter equation (Equ. 20) for these cases. Although the non-dimensional parameter F does not work well for high cloud cover fractions; fortunately, the periods for these points fit the temperature parameter curve (Equ. 22).

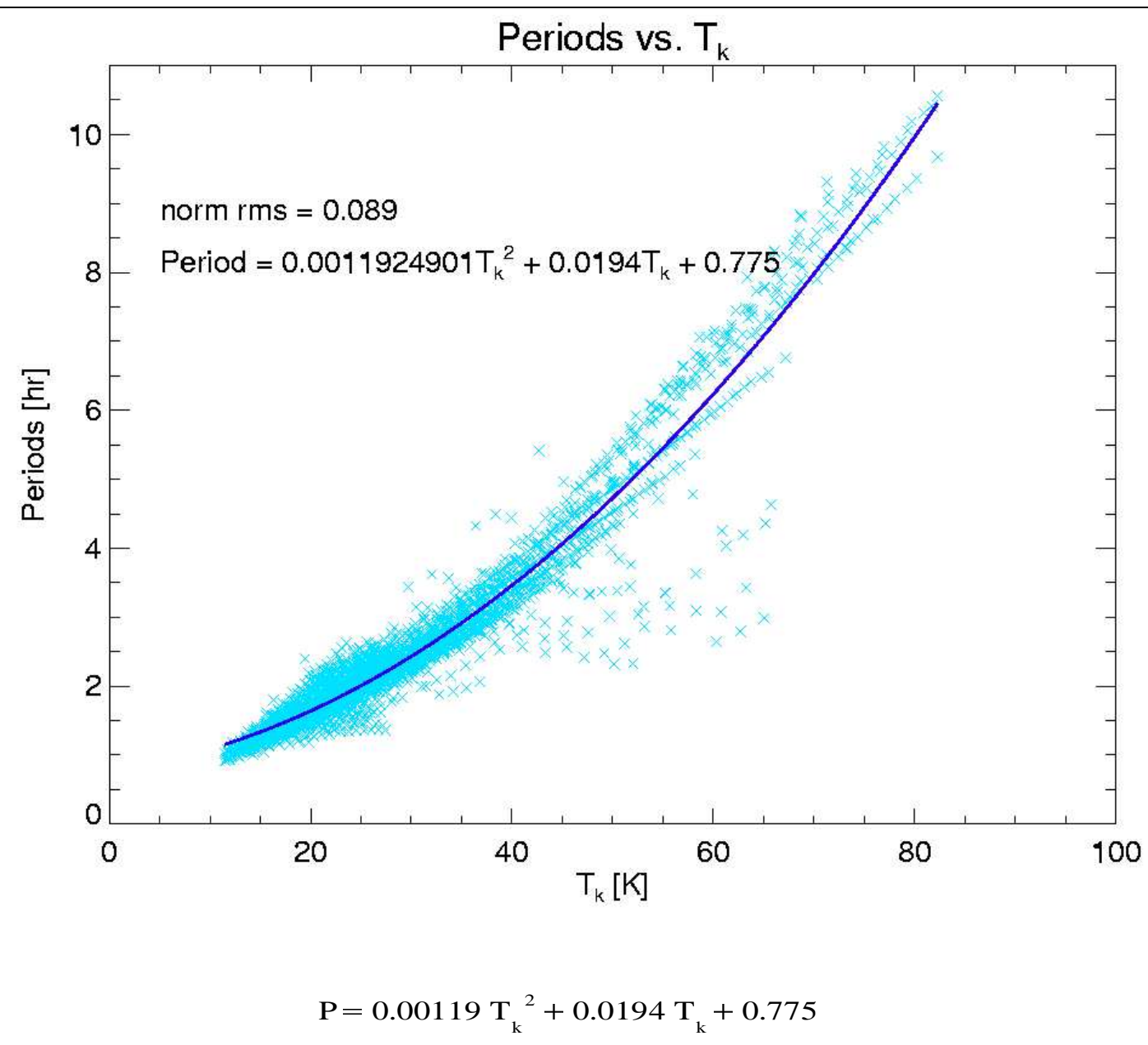

Fig. 8. Periods vs. the temperature parameter

The velocity parameter (Equ. 23) has also been studied, but no definite trend has been identified.

$$
\text { Velocity }: \mathrm{U}_{\mathrm{k}}[\mathrm{m} / \mathrm{s}]=\sqrt{\mathrm{h} * \frac{-1}{\rho} \frac{\partial \mathrm{P}}{\partial \mathrm{s}}}=\sqrt{-\mathrm{h} * \mathrm{PGF}}=\sqrt{\mathrm{h} * \mathrm{f} * \mathrm{u}_{\mathrm{g}}}
$$

Amplitudes and transition times have been plotted versus the non-dimensional number $\mathrm{F}$ and temperature parameter $T_{k}$. No discernable trend can be seen for the transition times, and 
thus we conclude that our method of defining transition times could be suspect. Amplitude versus the time parameter $\boldsymbol{\tau}_{\mathrm{b} 1}$ and similarly the non-dimensional parameter $\mathrm{F}$ group nicely with respect to cloud cover fraction, but a sufficient amount of stray points for low cloud cover fractions cause poorly-fitted curves (Fig. 9). In cases of low $|\mathrm{PGF}|$, a linear relationship between amplitude and the temperature parameter $T_{k}$ can be found. For high $|P G F|$, there is a much broader spread in amplitude, and thus a reliable single parameterization cannot be found at this time (Fig. 9d).

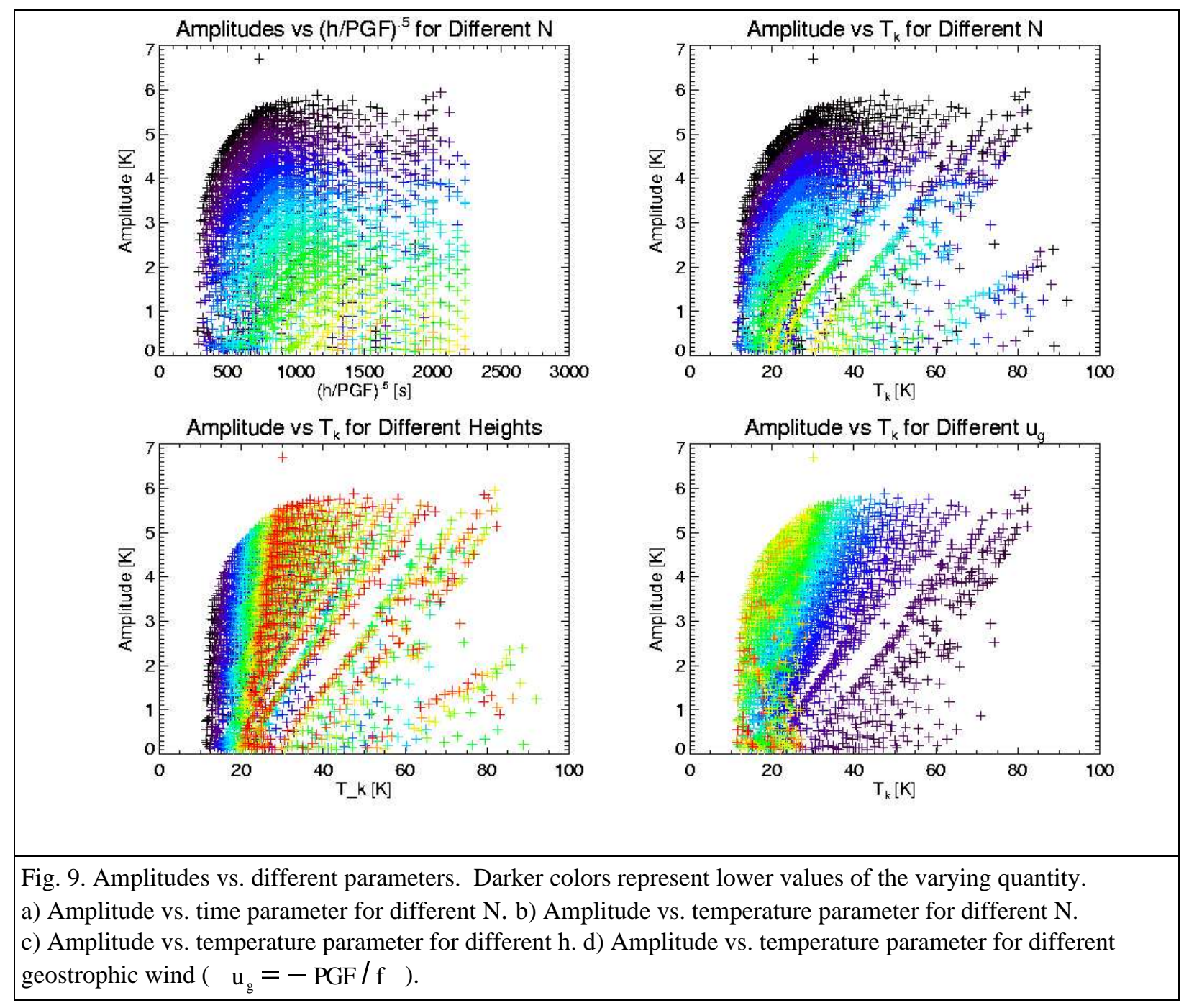

\section{Time-dependent input parameters}

a. Constant values with Addition Noise

The model has also been run using time-dependent input parameters. The values of these parameters are similar to the time-independent parameters; however, some fluctuation/noise with a maximum magnitude has been added. Table 3 lists how these parameters have been varied. 
Table 3. Time-dependent parameters and the amount of fluctuations added.

\begin{tabular}{|l|c|c|c|}
\hline \multicolumn{1}{|c|}{ Parameter } & Range & Increment & Magnitude of Noise \\
\hline$|\mathrm{PGF}|\left[\mathrm{m} / \mathrm{s}^{2}\right]$ & 0 to $6.0 * 10^{-4}$ & 0 & $0.1 * 10^{-4}, 0.5 * 10^{-4}, 1.0 * 10^{-4}$ \\
\hline Cloud Cover Fraction [-] & 0.0 to 1.0 & 0.05 & $.05, .1$ \\
\hline Boundary Layer Height $[\mathrm{m}]$ & 40 to 200 & 10 & 5,10 \\
\hline
\end{tabular}

A comparison of the periods for pressure gradient forces with different amounts of noise versus the temperature parameter shows that the period decreases overall as the magnitude of the noise increases (Fig. 11). Also the spread of data points tighten as the magnitude of the noise increases.
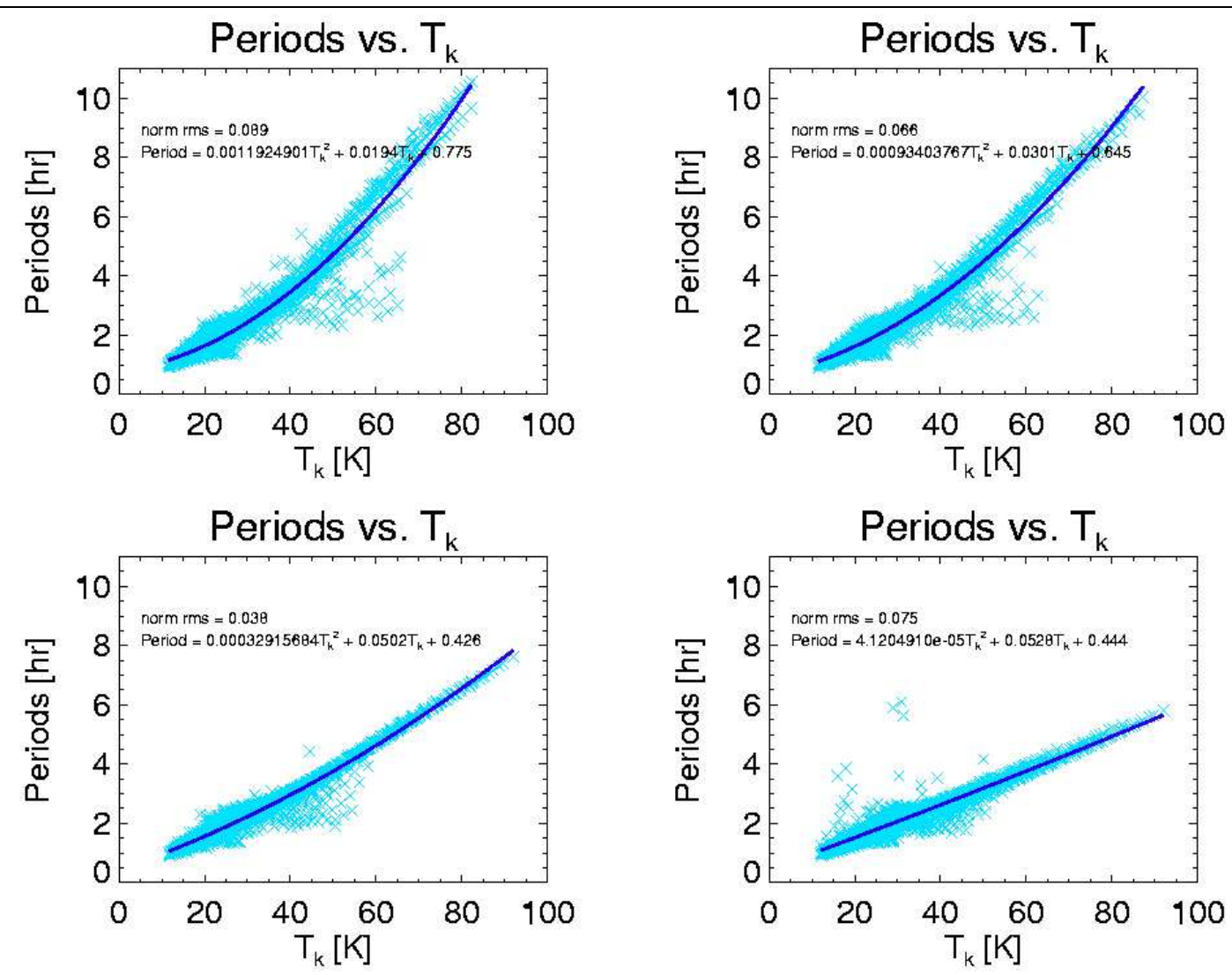

Fig. 10. Periods vs. the temperature parameter for time-dependent pressure gradient forces. a) In the top left plot, the pressure gradient force is constant in time. b). The top right plot represents simulations with $|\mathrm{PGF}|$ fluctuating with a maximum magnitude of $1.0 * 10^{-5} \mathrm{~m} / \mathrm{s}^{2}$.c)The bottom left plot represents simulations with $|\mathrm{PGF}|$ fluctuating with a maximum magnitude of $5.0 * 10^{-5} \mathrm{~m} / \mathrm{s}^{2}$. d) The bottom right plot represents simulations with $|\mathrm{PGF}|$ fluctuating with a maximum magnitude of $1.0 * 10^{-4 \mathrm{~m}} / \mathrm{s}^{2}$. 
As the fluctuations in pressure gradient force become too great $\left(\sim 1.0 * 10^{-4} \mathrm{~m} / \mathrm{s}^{2}\right)$, the accuracy of the period versus the non-dimensional parameter for high cloud cover fraction are rather poor. In summary, Table 4 lists when to use the appropriate parameter in determining the periods of intermittency.

Table 4. The appropriate usage of the non-dimensional and temperature parameters.

\begin{tabular}{|c|c|c|c|c|c|c|c|c|c|c|}
\hline $\begin{array}{c}\text { Max. } \\
\text { Fluct of } \\
\text { PGF } \\
10^{-4} \\
\mathrm{~m} \mathrm{~s}^{-2}\end{array}$ & $\begin{array}{c}\text { Use Eqn } \\
\text { when: }\end{array}$ & $a_{1}$ & $a_{2}$ & $a_{3}$ & $a_{4}$ & $a_{5}$ & $\begin{array}{c}\text { Use Eqn (25) when: } \\
(|\mathrm{PGF}| \text { measured in } \\
\left.\mathrm{m} \mathrm{s}^{-2}\right)\end{array}$ & $b_{1}$ & $b_{2}$ & $b_{3}$ \\
\hline 0.0 & $\mathrm{~N}<=.75$ & 1.45 & 245. & 0.337 & 230. & 0.99 & $\begin{array}{r}|\mathrm{PGF}|>=1.25 \mathrm{E}-04 \\
\& \mathrm{~N}>=.4\end{array}$ & $1.19 \mathrm{E}-03$ & $1.94 \mathrm{E}-02$ & 0.775 \\
\hline 0.1 & $\mathrm{~N}<=.9$ & 1.42 & 217. & 0.399 & 207. & 1.07 & $|\mathrm{PGF}|>=1.25 \mathrm{E}-04$ & $9.34 \mathrm{E}-04$ & $3.01 \mathrm{E}-02$ & 0.645 \\
\hline 0.5 & $\mathrm{~N}<=.75$ & 1.37 & 164. & 0.504 & 150. & 1.27 & $\begin{array}{r}|\mathrm{PGF}|>=1.25 \mathrm{E}-04 \\
\& \mathrm{~N}>=.4\end{array}$ & $3.2 \mathrm{E}-04$ & $5.02 \mathrm{E}-02$ & 0.426 \\
\hline 1.0 & $\mathrm{~N}<=.30$ & 0.84 & 124. & 0.265 & 108. & $\begin{array}{r}1.35 \\
|\mathrm{PGF}|>=1.25 \mathrm{E}-04 \\
\& \mathrm{~N}>.3\end{array}$ & $4.12 \mathrm{E}-05$ & $5.28 \mathrm{E}-02$ & 0.444 \\
\hline
\end{tabular}

$$
\mathrm{P}=\mathrm{a}_{1} \mathrm{~N}^{2}-\left(\mathrm{a}_{2} \mathrm{~F}+\mathrm{a}_{3}\right) \mathrm{N}+\mathrm{a}_{4} \mathrm{~F}+\mathrm{a}_{5}
$$

where $\mathrm{F}$ is the non-dimensional parameter defined in equation 18.

$$
P=b_{1} T_{k}^{2}+b_{2} T_{k}+b_{3}
$$

where $T_{k}$ is the temperature parameter defined in equation 21 .

Although the fluctuations in the pressure gradient force affect the surface temperature periods, they do not change the amplitude distribution. The only exception occurs when the added fluctuations are the same order of magnitude as the original pressure gradient force. In these cases, the amplitudes that are originally less than 2 degrees Kelvin increase by a couple degrees.

In contrast to these results, the fluctuations in boundary layer heights and cloud cover fractions alter the amplitudes of the timeseries but not the general period distribution. Due to the variability in amplitudes, the period-finding method is modified by taking the Fast Fourier transform of the timeseries from the transition time of the constant input case to the end of the timeseries. The weakness of this method is that it is based on the accuracy of the transition time 
calculated in the constant input case. However, it can be noted that all transition times for intermittent timeseries in the constant case are less than 26 hours. This is a reasonable time, and since most of the periods are less than 5 hours an adequate number of cycles will be available to compute a reasonable period.

The last plot in Figure 11 is an example of a boundary layer height input timeseries with an additional maximum fluctuation of $10 \mathrm{~m}$. The middle plot is the corresponding model output for this fluctuating input height. Comparing the surface temperature timeseries (solid line) to that of the top plot, which has constant boundary layer height input, notice that the amplitude in the middle plot is not periodic and in fact resembles the observational data in Figure 1.

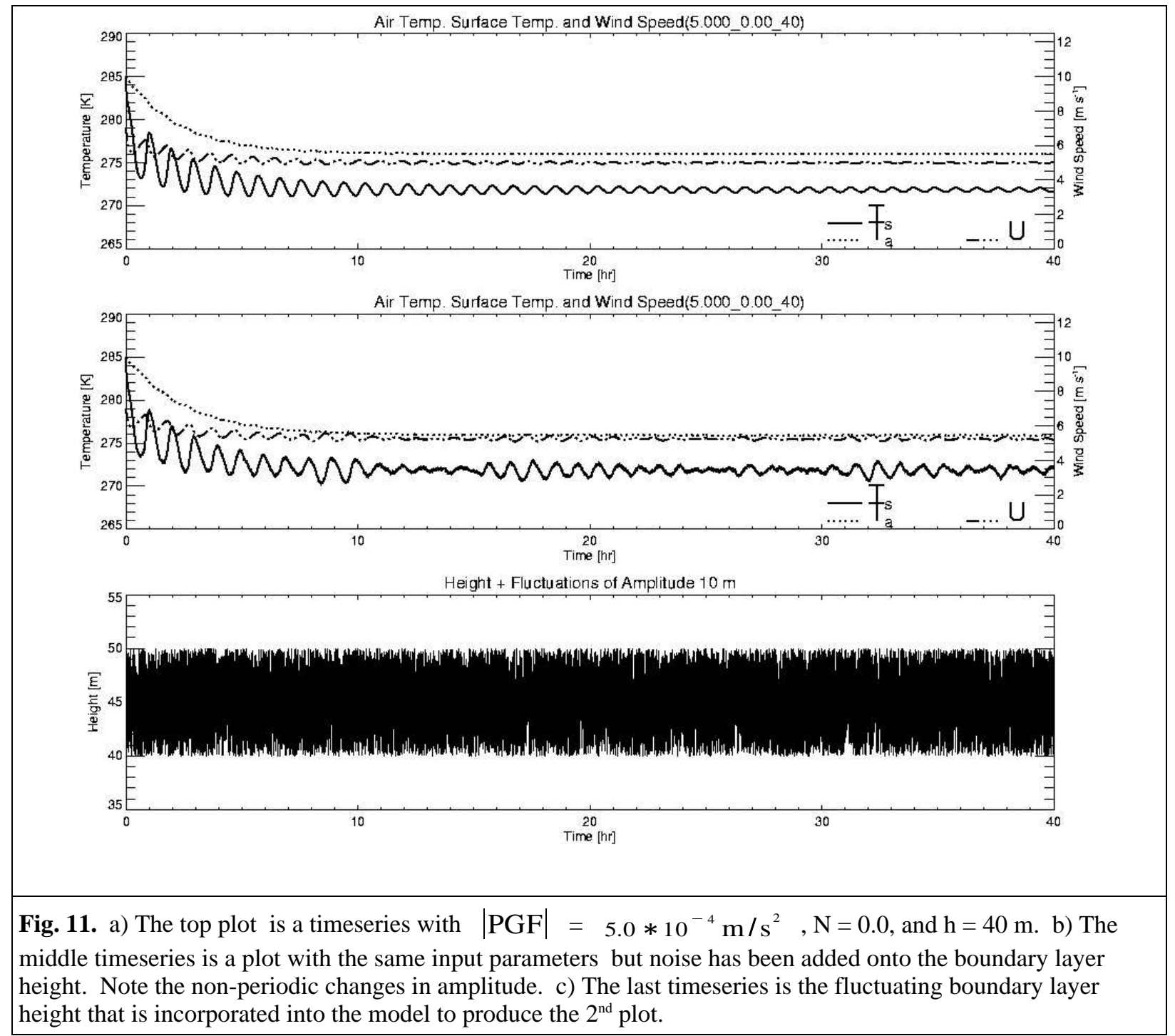

Interestingly, varying the boundary layer height or cloud cover fraction in time reduces the number of cases where the period is above 5 hours. In looking at the period vs. temperature parameter plot (Fig. 12), a smaller curve has formed below the main fit. 


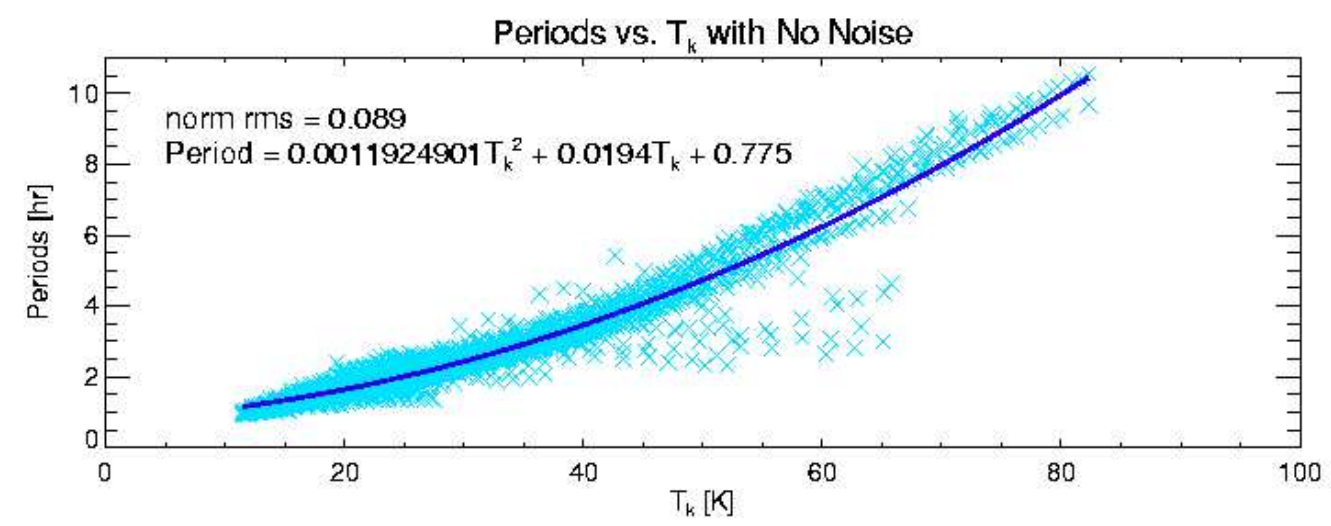

Periods vs. $\mathrm{T}_{k}$ for $\mathrm{N}$ with Additional Max Noise of .05

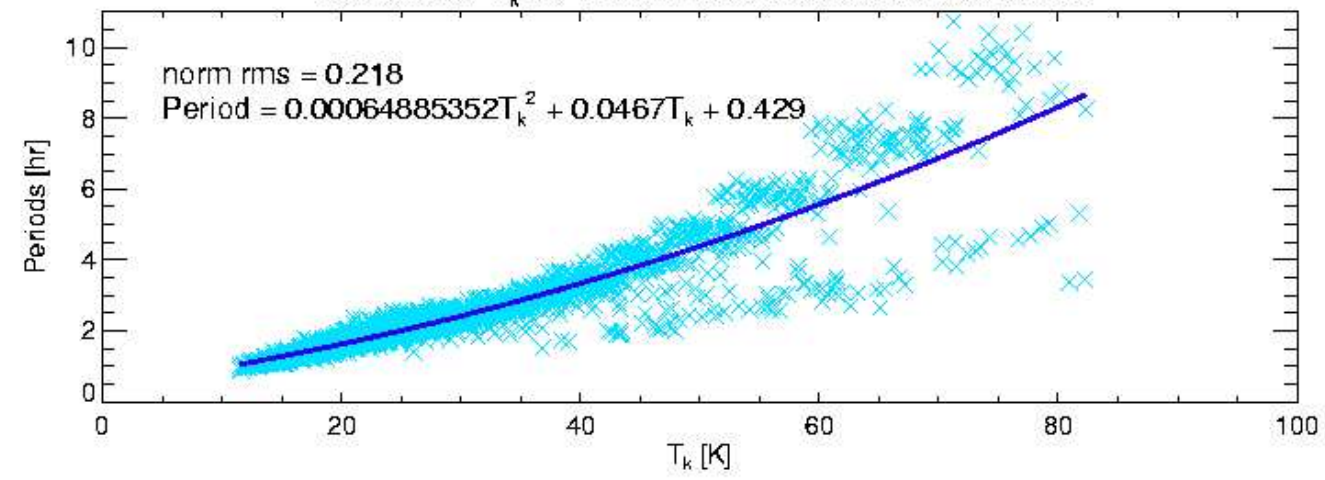

Periods vs. $\mathrm{T}_{\mathrm{k}}$ for $\mathrm{N}$ with Additional Max Noise of .1

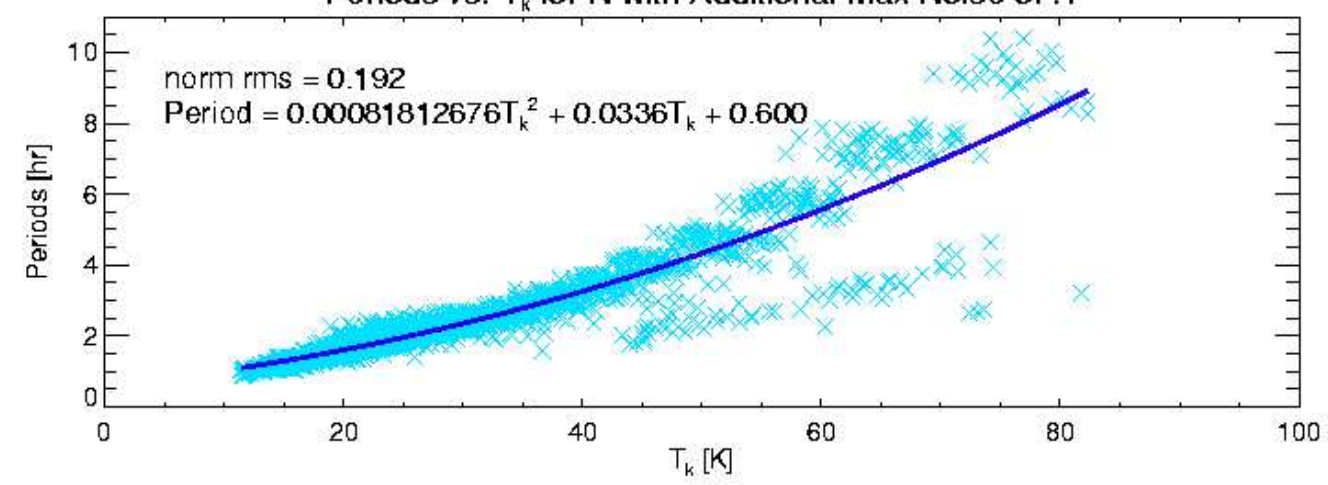

Fig. 12. Periods vs. temperature parameter. a) The top plot has constant in time inputs. b) The middle plot has time-dependent boundary layer heights with a maximum fluctuation of $10 \mathrm{~m}$. c) The last plot has time-dependent cloud cover fractions with a maximum fluctuation of .1. 
As mentioned previously, the amplitudes for the fluctuating $\mathrm{h}$ and $\mathrm{N}$ cases are not very uniform over time. An average amplitude is used to compare the constant and fluctuating input cases. Fluctuations in h do not seem to affect the average amplitudes; however, the amplitudes do decrease as the fluctuations in $\mathrm{N}$ get larger (Fig. 13).

b. Linearly increasing values with and without fluctuations

Another interesting input to the model is a linearly increasing $|\mathrm{PGF}|$ from

$1.0 * 10^{-4} \mathrm{~m} / \mathrm{s}^{2}$ to $7.0 * 10^{-4} \mathrm{~m} / \mathrm{s}^{2}$ with and without fluctuations. The two timeseries

(Fig. 14ab) do not appear to differ much, and as expected the oscillations begin to die off as the $|\mathrm{PGF}|$ reaches $5.0 * 10^{-4} \mathrm{~m} / \mathrm{s}^{2}$.

Observationally, the height of the stable boundary layer deepens (increases) further into the night. In the future, running the model with this input would be interesting since fluctuations in the boundary layer height affect the amplitude of the timeseries. 

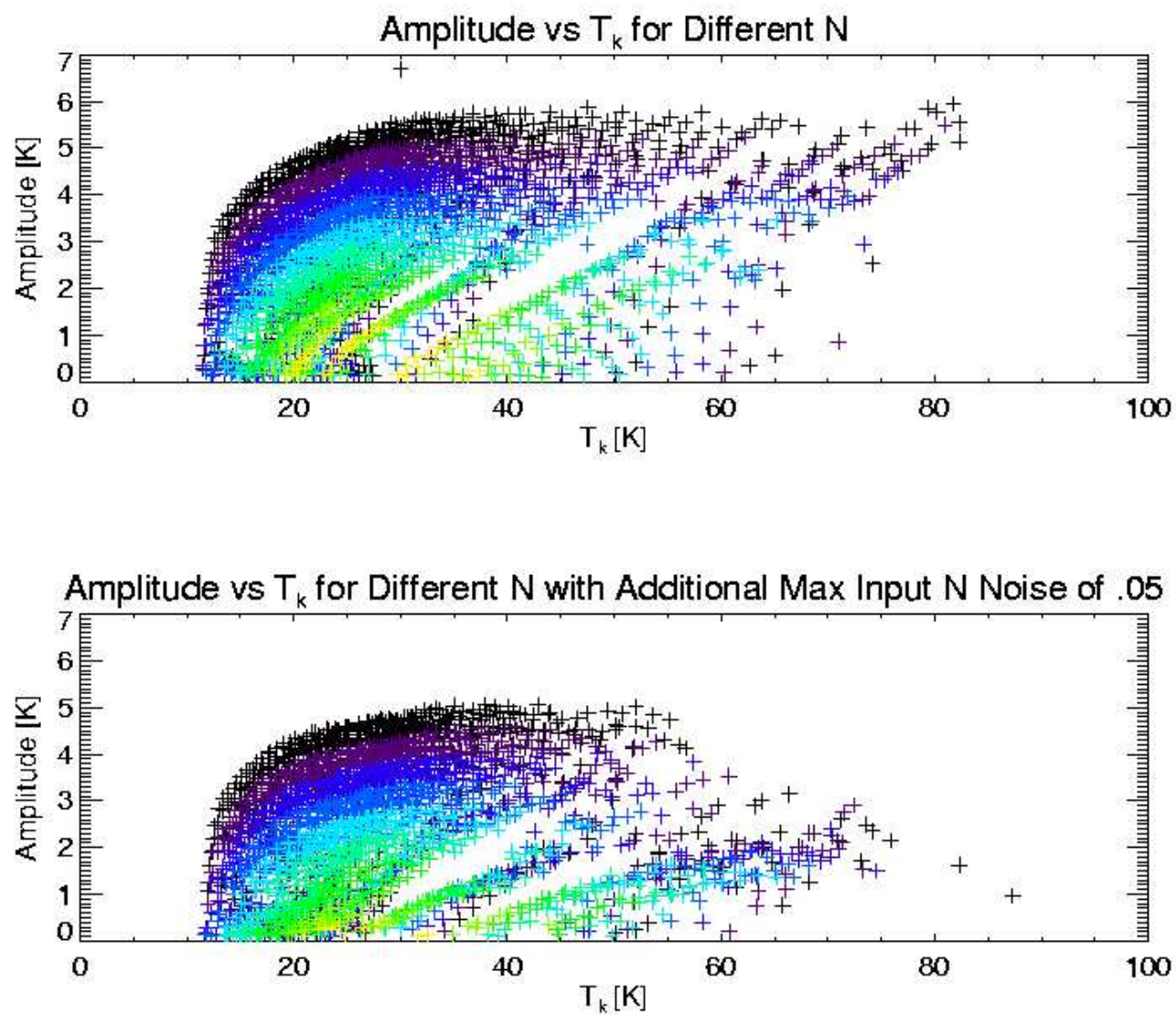

Amplitude vs $\mathrm{T}_{k}$ for Different $\mathrm{N}$ with Additional Max Input $\mathrm{N}$ Noise of .1

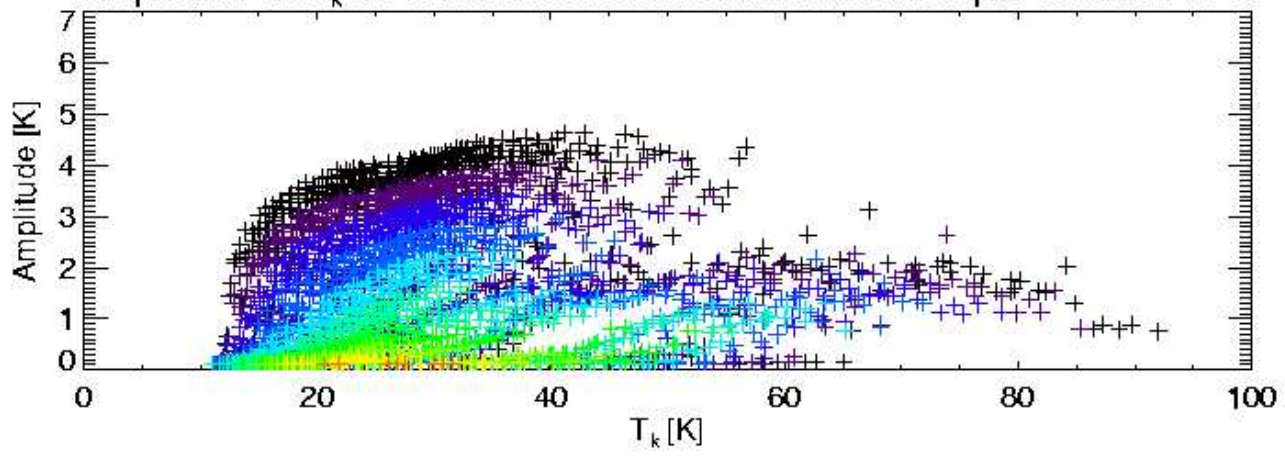

Fig. 13. Amplitudes vs. temperature parameter. The darker data points (black, purple) refer to simulations with an average low cloud cover fraction while the lighter ones (green, yellow, red) refer to simulations with an average high cloud cover fractions. a) The top plot has constant in time inputs. b) The middle plot has time-dependent cloud cover fraction inputs with a maximum fluctuation of .05. c) The last plot has time-dependent cloud cover fraction inputs with a maximum fluctuation of .1. 


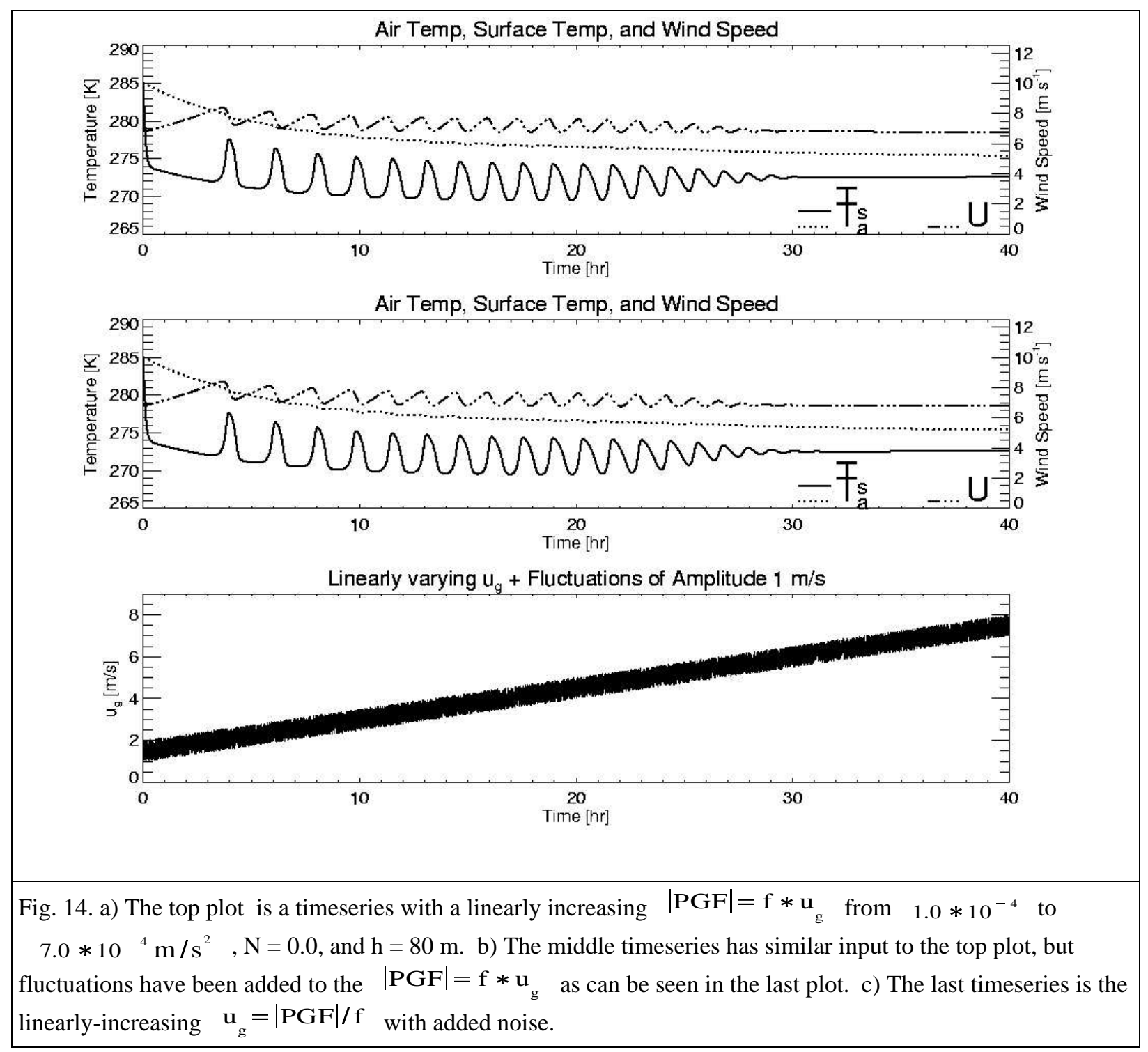




\section{1 D model}

Another dimension has been incorporated into the model. By adding the equation for the wind in the $\mathrm{v}$ direction, the hope is to include the influence of the inertial oscillations of the wind speeds in the $\mathrm{u}-\mathrm{v}$ plane. The model equations are modified to become the following:

$$
\begin{aligned}
& \frac{\partial u}{\partial t}=f *\left(-v_{g}+v\right)-\frac{1}{h} \frac{\kappa^{2}}{\left(\ln \frac{\tilde{h}}{z_{0}}\right)^{2}} u\left(u^{2}+v^{2}\right)^{.5} f\left(R_{b}\right) \\
& \frac{\partial v}{\partial t}=f *\left(u_{g}-u\right)-\frac{1}{h} \frac{\kappa^{2}}{\left(\ln \frac{\tilde{h}}{z_{0}}\right)^{2}} v\left(u^{2}+v^{2}\right)^{5} f\left(R_{b}\right)
\end{aligned}
$$

The temperature equations remain the same; however, the wind speed $U$ now refers to the total magnitude of the wind speed, $U=\sqrt{u^{2}+v^{2}}$.

Unfortunately, the results of several simulations do not show intermittent turbulence whereas the $0 \mathrm{D}$ equivalent simulations do. I have also run the model using a critical Richardson's number of .4 and .5. The bulk Richardson's number consistently exceeds these numbers early in the timeseries and never recovers. 


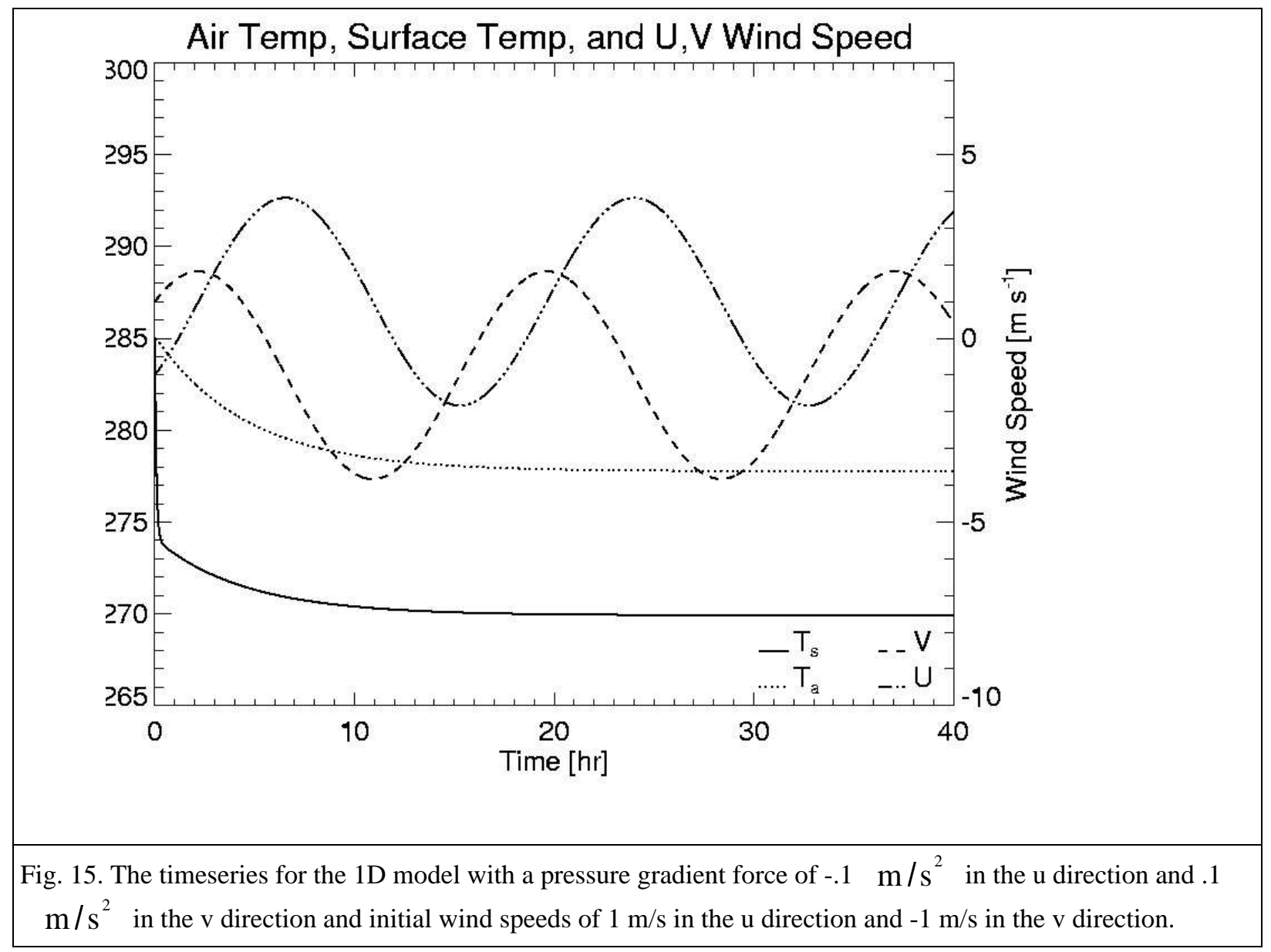

\section{Bulk Richardson number}

In the original model, the critical Richardson number is .2. However, in large eddy simulations, turbulence has also been observed at larger bulk Richardson numbers. Simulations for a limited range of pressure gradient forces have also been run using a critical Richardson number of .4 and .5. In these cases, the stability function never disappears, and thus no intermittency occurs.

\section{Conclusion/Summary}

This model explores the interaction between a cooling vegetated surface and the lower atmosphere. Neglecting any possibility of intermittence generated from the top of the stable boundary layer, the frequency of intermittency can be defined as a function of the three input quantities - pressure gradient force, cloud cover fraction, and boundary layer height. It is not clear if the amplitude of the intermittency and the time to reach a quasi-steady state can also be described as a function of the inputs.

In addition, time-dependent inputs have an effect on the overall intermittency. 
Fluctuations in the pressure gradient force have the most influence in decreasing the periods while varying cloud cover fraction decreases the amplitude of the intermittence. It is unclear whether the transition time is affected by the fluctuating inputs.

To gauge the sufficiency of this model, the results must be compared to experimental studies and models that include the forcing at the top of the stable boundary layer.

\section{Acknowledgments}

This work was performed under the auspices of the U.S. Department of Energy by University of California, Lawrence Livermore National Laboratory under Contract W-7405-Eng-48.

\section{References}

Derbyshire, S. H., 1999: Boundary-layer decoupling over cold surfaces as a physical boundary instability. Bound.-Layer Meteor., 90, 297-325

Stull, R. B., 1988. An Introduction to Boundary Layer Meteorology. Kluwer Academic Publisher, 666

van de Wiel, B.J.H., R.J. Ronda, A.F. Moene, H.A.R. De Bruin, and A.A.M. Holtslag, 2002a: Intermittent Turbulence and Oscillations in the Stable Boundary Layer over Land. Part I: A Bulk Model. J. Atmos. Sci., 59, 942-958.

, et al., 2002b: Intermittent Turbulence and Oscillations in the Stable Boundary Layer over Land. Part II: A System Dynamics Approach. J. Atmos. Sci., 59, 2567-2581. 